\title{
Sand fly fauna of Crete and the description of Phlebotomus (Adlerius) creticus n. sp. (Diptera: Psychodidae)
}

\author{
Vít Dvořák ${ }^{1 *}$, Nikolaos Tsirigotakis ${ }^{2}$, Christoforos Pavlou $^{2}$, Emmanouil Dokianakis ${ }^{2}$, Mohammad Akhoundi ${ }^{3}$, \\ Petr Halada ${ }^{4}$, Petr Volf ${ }^{1}$, Jérôme Depaquit ${ }^{5}$ and Maria Antoniou ${ }^{2}$
}

\begin{abstract}
Background: The Greek island of Crete is endemic for both visceral leishmaniasis (VL) and recently increasing cutaneous leishmaniasis (CL). This study summarizes published data on the sand fly fauna of Crete, the results of new sand fly samplings and the description of a new sand fly species.

Methods: All published and recent samplings were carried out using CDC light traps, sticky traps or mouth aspirators. The specific status of Phlebotomus (Adlerius) creticus n. sp., was assessed by morphological analysis, cytochrome $b$ (cytb) sequencing and MALDI-TOF protein profiling.

Results: Published data revealed the presence of 10 Phlebotomus spp. and 2 Sergentomyia spp. During presented field work, 608 specimens of 8 species of Phlebotomus and one species of Sergentomyia were collected. Both published data and present samplings revealed that the two most common and abundant species were Phlebotomus neglectus, a proven vector of Leishmania infantum causing VL, and Ph. similis, a suspected vector of $L$. tropica causing $\mathrm{CL}$. In addition, the field surveys revealed the presence of a new species, Ph. (Adlerius) creticus n. sp.

Conclusions: The identification of the newly described species is based on both molecular and morphological criteria, showing distinct characters of the male genitalia that differentiate it from related species of the subgenus Adlerius as well as species-specific sequence of cytb and protein spectra generated by MALDI-TOF mass spectrometry.
\end{abstract}

Keywords: Phlebotominae, Phlebotomus (Adlerius) creticus n. sp., Crete, Greece, Sand fly fauna

\section{Background}

Phlebotomine sand flies (Diptera: Psychodidae) are hematophagous insects that transmit the protozoan parasites Leishmania spp. as well as the bacterium Bartonella bacilliformis and viruses (phleboviruses, vesiculoviruses and orbiviruses) [1]. Four medically important Leishmania species circulate in various regions of the Mediterranean basin: L. infantum causing both zoonotic visceral $(\mathrm{VL})$ and anthroponotic cutaneous (CL) leishmaniasis in humans

\footnotetext{
${ }^{*}$ Correspondence: icejumper@seznam.cz

1 Department of Parasitology, Faculty of Science, Charles University, Prague, Czech Republic

Full list of author information is available at the end of the article
}

and canine leishmaniasis in dogs (CanL); L. major causing zoonotic CL; L. tropica causing anthroponotic or zoonotic CL [2-4] and the recently introduced $L$. donovani causing both anthroponotic VL and CL [5].

Crete is endemic for VL and CanL caused by L. infantum, with an increasing number of CL every year caused by $L$. tropica whilst the danger of the introduction of new species/zymodemes is enhanced by the arrival of refugees from endemic areas [6]. The key factor for determining the distribution and spread of leishmaniases is by recording the geographical distribution and abundance of the medically important sand fly vectors. Generally, in Greece, proven or suspected vectors are Ph. similis Artemiev \& Neronov, 1984 for Leishmania tropica and Ph. 
perfiliewi Parrot, 1930, Ph. tobbi Adler \& Theodor, 1930 and Ph. neglectus Tonnoir, 1921 for L. infantum [7].

The main aims of this study were to review historical data on the sand fly fauna of Crete and describe a new Phlebotomus (Adlerius) species sampled during surveys carried out from 2014 to 2019. To confirm the status of the new species, in addition to morphological and genetic criteria, for the first time, protein profiling using MALDI-TOF mass spectrometry was also deployed.

\section{Methods}

\section{Sand fly data}

All published data recording sand fly presence in Crete were gathered. The literature search concerning the review follows the Prisma Journal Publishing protocol workflow [8]. PubMed, Web of Science, Google Scholar databases and web searches were screened from 1910 to 30 November 2019, using the following keywords: Phlebotominae, Phlebotomus, Crete, Sergentomyia, Greece, sand flies, CDC light traps, sticky traps, mouth aspirator, electric aspirator. Full text articles in English containing information on phlebotomine sand flies from Crete were selected. Other articles, including those in other languages, that contain desired information were also included, based on the cited databases knowledge of the authors. Samplings were carried out using CDC miniature light traps (John W. Hock Co., Gainesville, FL, USA), Sticky Traps (A4 paper coated with castor oil) or mouth aspirators. The sampling sites were mostly animal farms, houses, schools, churches, deserted houses, wells, caves and rural areas with different cultivations or wild vegetation.

\section{Study areas and sampling}

The new samplings were carried out in five study areas, two in Heraklion, two in Chania and one in Lasithi between 2014 and 2019 (Table 1). The study areas were Fodele and Foinikia in Heraklion prefecture, Agia Roumeli and Botanical Gardens in Chania and Xerokampos in Lasithi. The CDC miniature light traps equipped with a fine net cage were used for all the samplings. In all sampling areas, 7-9 light traps were placed in different microhabitats for one to two days. The light traps were set $1.5 \mathrm{~h}$ before sunset and were collected $2 \mathrm{~h}$ after dawn. Specifically, in Fodele 9 light traps for 2 sampling nights in May 2019 were used, in Foinikia 9 traps for 1 night in August of 2018, in Agia Roumeli 7 traps for 2 sampling nights in May of 2014, and in Botanical Garden 9 traps for 2 sampling nights in August of 2019. In Xerokampos two samplings were carried out during April of 2014 and in May of 2019 using 9 traps for 2 sampling nights.

\section{Sand fly morphological identification}

The specimens were stored in vials containing absolute ethanol HPLC grade (Thermo Fischer Scientific, Gloucester, UK) at room temperature prior to mounting, except for the specimens later analyzed by MALDI-TOF protein profiling which were stored in $70 \%$ molecular grade ethanol at $-20{ }^{\circ} \mathrm{C}$ before further processing. The samples were divided into specimens mounted in toto and specimens processed for molecular biology. In the latter case, the head, thorax including wings and genitalia were removed and placed in a drop of ethanol before their processing similar to specimens mounted in toto, while the other parts of the body were kept in ethanol for molecular analysis. Soft tissues were lysed in a bath of $\mathrm{KOH} \mathrm{10 \% ,} \mathrm{then} \mathrm{bleached} \mathrm{in} \mathrm{Marc-André} \mathrm{solution,} \mathrm{and}$ mounted between microscope slide and cover slide in Euparal $^{\circledR}$ for species identification after dehydration in graded ethanol series [9]. Some specimens were mounted immediately after clearing in Marc-André solution or in high viscosity CMCP-10 medium (Polysciences, Inc., Warrington, PA, USA). Morphological identification was performed under a BX61 microscope (Olympus, Japan). Measurements and counts were taken using the Stream Motion software (Olympus, Japan) and a video camera connected to the microscope. Identification was performed based on the keys available for Crete and adjacent regions [10-14].

The terminology adopted for the characters is the most recent one for phlebotomine sand flies [15]. The following measurements were made for the specimens of the new species for both sexes: flagellomeres 1, 2 and 3, labrum-epipharynx. For males, we also measured the lengths of the parameral sheath, the distance from the tubercle to the tip of the parameral sheath (indicated as the distance from the tip of the aedeagus to the subterminal tooth by Artemiev [10]), sperm pump, aedeagal ducts, gonocoxite, beginning and ending of the tuft of internal setae of the gonocoxite, number of internal setae of the gonocoxal tuft and area of the internal tuft of setae of the gonocoxite (Fig. 1).

The percentage of tuft length $v s$ gonocoxite length was calculated as follows: tuft length $\times 100$ )/gonocoxite length. The median tuft position $v s$ gonocoxite was calculated as follows: beginning of the tuft of internal setae of the gonocoxite + tuft length $/ 2) \times 100 /$ gonocoxite length Drawings were made using a camera lucida.

\section{DNA extraction and cytochrome $b$ mtDNA sequencing}

Following morphological identification, DNA was extracted using DNeasy Blood \& Tissue Kit (Qiagen, Hilden, Germany) from 16 individuals (males and females) of Ph. (Adlerius) creticus n. sp. collected during previous surveys at four localities in Crete as well as from 
two specimens of Ph. simici Nitzuescu, 1931 from Crete and three specimens of Ph. balcanicus Theodor, 1958 from Iran. $c y t b$ PCR assays were performed using primers and conditions described by Esseghir et al. [16] and sequenced both directions according to Sanger's method using the same primers as in the PCR assay.

\section{Alignment and genetic distances}

The newly generated sequences data were aligned with cytb sequences available on GenBank (Table 2), which belong to Adlerius spp. [17-21]. Multiple sequence alignments were performed using ClustalW [22] as implemented in MEGA7 [23]. Genetic distances were calculated between and within species using Tamura-Nei model [24], also in MEGA7 [23].

\section{Phylogenetic analyses}

The optimal nucleotide substitution models were identified using PartitionFinder (PF) v.2.1.1 [25]. We ran PF two different times using the greedy search algorithm with linked branch lengths in calculations of likelihood scores under the Bayesian information criterion (BIC). The difference between these two runs was the restriction of candidate models to only those that are available in either MrBayes v.3.2.6 [26] or PhyML v.3.0 [27]. The models which included both gamma distribution $(\mathrm{G})$ and invariable sites (I) were ignored [28].

Phylogenetic trees were constructed using Bayesian Inference (BI) and Maximum Likelihood (ML) methods. The BI analysis was performed in MrBayes v3.2.6 [26] with 4 runs and 8 chains per run for 10,000,000 generations, with a sampling frequency of 100 . From the sampled trees, 25\% were discarded as 'burn-in' phase and therefore, a majority rule consensus tree relied on the remaining trees and posterior probabilities were calculated as the percentage of samples recovering any particular clade [29]. ML analysis was performed with PhyML v.3.0 [27] with nearest-neighbor-interchange search, bio-neighbor joining starting tree under the suggested models selected in PF. Bootstrap values were estimated by 1000 replicates [30]. Phlebotomus perfiliewi represented the outgroup in the phylogenetic analyses.

\section{MALDI-TOF protein profiling}

Samples that were subjected to MALDI-TOF MS analysis were processed as previously described [31]. It was demonstrated that mass spectrometry-based approach is not suitable for specimens collected by sticky traps [32]; therefore, only specimens collected by CDC light traps were included into the assay. Within one month after the collection in the field, specimens stored in $70 \%$ ethanol were dissected, heads and terminalia were mounted by CMCP-10 mounting medium (Polysciences) for morphological typing, rest of abdomens were stored for DNA isolation and $c y t b$ sequencing as described above and thoraxes were ground by a manual BioVortexer homogenizer (BioSpec, Bartlesville, USA) with sterile disposable pestles in $10 \mu \mathrm{l}$ of $25 \%$ formic acid. Two $\mu \mathrm{l}$ of the homogenate were mixed with $2 \mu \mathrm{l}$ of freshly prepared MALDI matrix, an aqueous $60 \%$ acetonitrile/0.3\% TFA solution of sinapinic acid $(30 \mathrm{mg} / \mathrm{ml}$; Sigma-Aldrich, St. Louis, USA). One $\mu$ l of this mixture were spotted directly onto a steel MALDI plate in duplicates. Protein mass spectra were measured using an Autoflex Speed MALDITOF spectrometer (Bruker Daltonics, Billerica, USA) in a mass range of $4-25 \mathrm{kDa}$ and compared by FlexAnalysis 3.4 software. For cluster analysis and species identification, the protein profiles were processed using MALDI Biotyper 3.1 and searched against an in-house database that comprises reference spectra of 23 different sand fly species including following Adlerius species: Ph. arabicus Theodor, 1953, Ph. balcanicus, Ph. halepensis Theodor, 1958 and Ph. simici.

\section{Results}

\section{Sand fly data}

The first published study of the sand fly fauna of Crete appeared in 1910 and since then, 16 more works were published, revealing the presence of 10 Phlebotomus spp. and 2 Sergentomyia spp. (Table 3).

\section{Sand fly sampling in 2014-2019}

Overall, 608 sand fly specimens were collected which corresponded to nine different species with the most common and abundant species being Se. minuta and

Table 1 The study areas of the 2014-2019 samplings in Crete

\begin{tabular}{llll}
\hline Study area & Latitude & Longitude & Date \\
\hline Xerokampos & $35^{\circ} 3^{\prime} 29.37^{\prime \prime} \mathrm{N}$ & $26^{\circ} 14^{\prime} 27.14^{\prime \prime} \mathrm{E}$ & 14-16 April 2014 \\
Agia Roumeli & $35^{\circ} 13^{\prime} 24.77^{\prime \prime} \mathrm{N}$ & $23^{\circ} 56^{\prime} 7.53^{\prime \prime} \mathrm{E}$ & $11-12$ May 2014 Caves \\
Foinikia & $35^{\circ} 16^{\prime} 31.73^{\prime \prime} \mathrm{N}$ & $25^{\circ} 6^{\prime} 16.48^{\prime \prime} \mathrm{E}$ & 28 August 2018 \\
Fodele & $35^{\circ} 22^{\prime} 53.93^{\prime \prime} \mathrm{N}$ & $24^{\circ} 57^{\prime} 28.27^{\prime \prime} \mathrm{E}$ & $24-26$ May 2019 \\
Xerokampos & $35^{\circ} 3^{\prime} 29.37^{\prime \prime} \mathrm{N}$ & $26^{\circ} 14^{\prime} 27.14^{\prime \prime} \mathrm{E}$ & 28-30 May 2019 \\
Botanical Garden & $35^{\circ} 25^{\prime} 6.69^{\prime \prime} \mathrm{N}$ & $23^{\circ} 56^{\prime} 23.08^{\prime \prime} \mathrm{E}$ & 2-3 August 2019 Caves trees \\
\hline
\end{tabular}




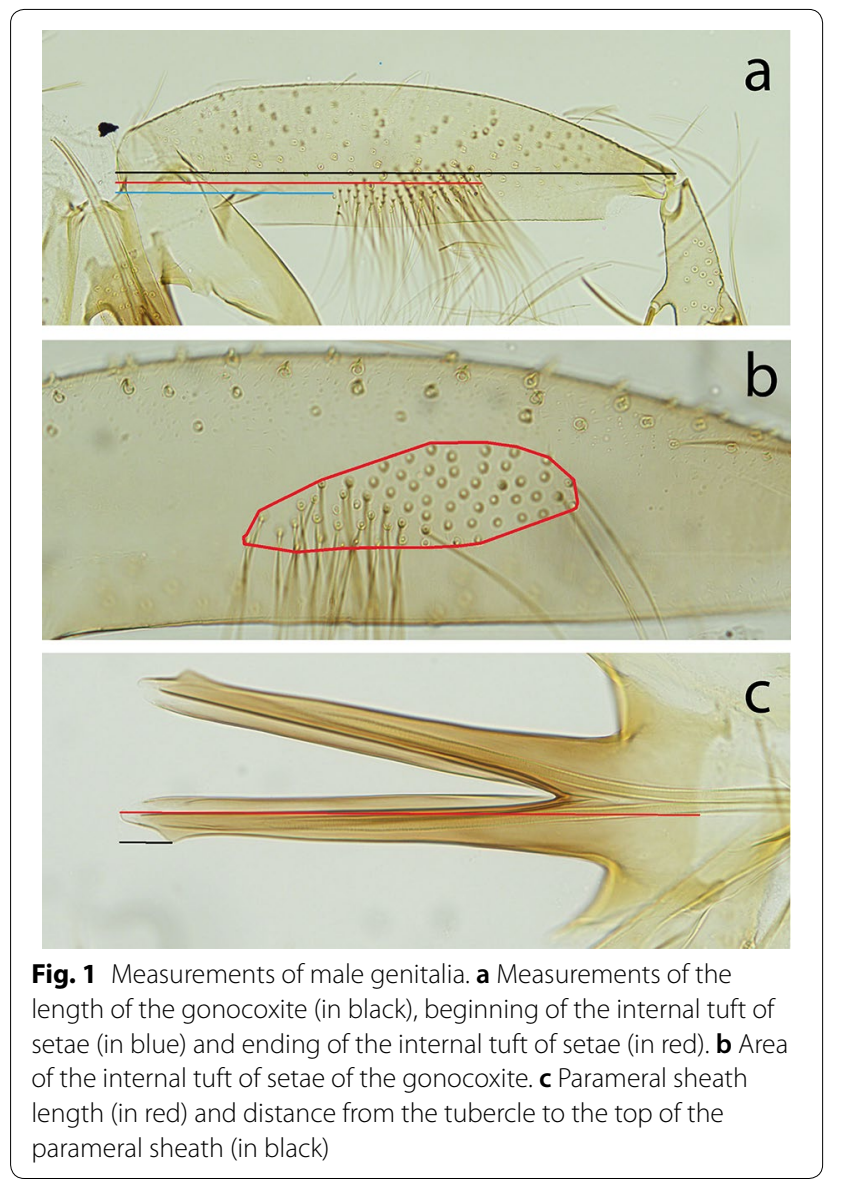

Ph. neglectus (Table 4). In addition to species known in Crete, 151 specimens of $P h$. (Adlerius), morphologically close to $\mathrm{Ph}$. balcanicus and Ph. zulfagarensis were identified. These specimens were further analysed and their morphological and molecular identification is described below.

Table 5 sums up the total number of specimens, of each species, caught in present samplings and previous publications. More than 30,000 specimens have been reported and about $63.27 \%$ of them were identified as the medically important species $P h$. neglectus. Moreover, a significant proportion of the specimens were identified as $\mathrm{Ph}$. similis $(17.4 \%)$ and $P h$. papatasi $(9.49 \%)$. In all prefectures except Chania, Ph. neglectus $(>50 \%)$ and Ph. similis ( $30 \%)$ were the most common and abundant species. In Chania, Ph. papatasi was the most common and abundant species which comprised almost the $60 \%$ of the sand fly specimens (Fig. 2).

\section{Morphological typing of Ph. creticus n. sp}

Fifty-four male individuals collected by CDC light traps were used for the morphological analysis, originating from three localities (8 from Toplou, 23 from
Table 2 Information on specimens used for cytb sequencing analysis

\begin{tabular}{|c|c|c|c|}
\hline Sample & Geographical origin & Collection date & GenBank ID \\
\hline Crete12 & Crete, Xerokampos & 30 May 2019 & MT501623 \\
\hline Crete13 & Crete, Xerokampos & 30 May 2019 & MT501624 \\
\hline Crete14 & Crete, Xerokampos & 30 May 2019 & MT501625 \\
\hline Crete17 & Crete, Xerokampos & 30 May 2019 & MT501626 \\
\hline Crete18 & Crete, Xerokampos & 30 May 2019 & MT501627 \\
\hline Crete19 & Crete, Xerokampos & 30 May 2019 & MT501628 \\
\hline AR112 & Crete, Agia Roumeli & 11 May 2014 & MT501629 \\
\hline AR224 & Crete, Agia Roumeli & 11 May 2014 & MT501630 \\
\hline AR231 & Crete, Agia Roumeli & 11 May 2014 & MT501631 \\
\hline F235 & Crete, Fodele & 2013 & MT501632 \\
\hline Fb16 & Crete, Fodele & 2013 & MT501633 \\
\hline Fb19 & Crete, Fodele & 2013 & MT501634 \\
\hline BAGR2 & Crete, Toplou monastery & 11 August 1991 & MT501635 \\
\hline BAGR7 & Crete, Toplou monastery & 11 August 1991 & MT501636 \\
\hline BAGR4 & Crete, Toplou monastery & 11 August 1991 & MT501637 \\
\hline BAGR8 & Crete, Toplou monastery & 11 August 1991 & MT501638 \\
\hline BAIR4 & Iran, Kaleybar & July 2010 & MT501639 \\
\hline BAIR5 & Iran, Kaleybar & July 2010 & MT501640 \\
\hline BAIR100 & Iran, Kaleybar & July 2010 & MT552617 \\
\hline SICR2 & Crete, Messa Mouliana & 13 August 1991 & MT552618 \\
\hline SICR3 & Crete, Messa Mouliana & 13 August 1991 & MT552619 \\
\hline Ph. brevis & Iran & 1985 & HQ023282 \\
\hline Ph. turanicus & Afghanistan & 2009 & HM803195 \\
\hline Ph. halepensis & Iran & 2006-2007 & HQ391905 \\
\hline Ph. halepensis & Iran & 2005 & HQ023283 \\
\hline Ph. chinensis & China & na & HM747274 \\
\hline Ph. chinensis & China & na & HM747272 \\
\hline Ph. chinensis & China & na & HM747268 \\
\hline Ph. chinensis & China & na & HM747264 \\
\hline Ph. chinensis & China & na & HM747260 \\
\hline Ph.perfiliewi & Italy & na & KF680811 \\
\hline
\end{tabular}

na, not available

Xerokampos and 23 from Fodele). The descriptive statistics for 22 characters are given in Table 6. Eleven females from Xerokampos were used for the description, descriptive statistics for 6 characters are given in Table 7. To exclude a presence of two distinct populations, the normality of the distributions of each of the morphological characters was tested by Shapiro-Wilk test $(P>0.05)$ and was found not to be significantly different from normal.

The antennal formula in males shows variability. Of the 44 males examined exhibiting antennae, 36 have an antennal formula $2 / \mathrm{f} 1-\mathrm{f} 3,1 / \mathrm{f} 4$-f13 which appears as the most common formula. Five specimens exhibit the following formula: 2/f1-f4, 1/f5-f13 with very commonly one very small ascoid on f5. One specimen exhibits $2 /$ 
f1-f2, 1/f3-f13. One specimen exhibits 2/f1-f5, 1/f6-f13 with a small ascoid on both $\mathrm{f} 4$ and $\mathrm{f} 5$. Interestingly, one specimen exhibits $2 / \mathrm{f} 1-\mathrm{f} 4,1 / \mathrm{f} 5$-f13 on the left antenna and $2 / \mathrm{f} 1-\mathrm{f} 3+\mathrm{f} 5,1 / \mathrm{f} 4+\mathrm{f} 6-\mathrm{f} 13$ on the right one.

\section{Sequence analysis}

The $c y t b$ gene was successfully amplified and sequenced and the final dataset consisted of an alignment of $446 \mathrm{bp}$. The pairwise distances between species ranged from 0.044 to 0.188 , while the closest related species to Ph. creticus n. sp. appeared to be Ph. balcanicus with a mean distance of 0.044 . The mean distance within the Ph. creticus $\mathrm{n}$. sp. samples was 0.008 . The pairwise mean distances between and within species are provided in Table 8.

\section{Phylogenetic analyses}

The best-fit nucleotide substitution model for $c y t b$ was Hasegawa-Kishino-Yano (HKY) + I for all codon positions and for both MrBayes and PhyML. Both analyses led to phylogenetic trees with similar topologies and hence, only the consensus MrBayes tree including posterior probabilities and bootstrap values is presented here (Fig. 3). All species used in these analyses formed monophyletic clades and specifically, the specimens of $P h$. creticus $\mathrm{n}$. sp. formed a well-supported monophyletic clade. Phlebotomus creticus n. sp. appears to be more closely related to $\mathrm{Ph}$. balcanicus than the other species included in the analyses.

\section{MALDI-TOF protein profiling}

In total, 28 specimens of five Phlebotomus species from Xerokampos $(n=26)$ and Fodele $(n=2)$ were analysed: Ph. creticus n. sp. $(n=12)$, Ph. killicki $(n=1)$, Ph. neglectus $(n=5)$, Ph. similis $(n=7)$ and Ph. simici $(n=3)$. Reproducible protein spectra with a high number of intense signals within the mass range of $4-25 \mathrm{kDa}$ were generated for all analysed specimens. These protein profiles were species-specific and showed species-unique peaks that allowed reliable and conclusive differentiation of the analyzed specimens. Protein spectra of the specimens identified based on morphology as belonging to four known species were similar to the corresponding reference spectra of the respective species. Protein spectra of all Ph. creticus n. sp. specimens were identical and differed substantially from the spectra of other species as shown by a hierarchical cluster analysis (Fig. 4a).

Table 3 Publications on the sand fly fauna of Crete [34-50]

\begin{tabular}{|c|c|c|}
\hline Species & Reference & Prefecture \\
\hline Ph. (Larroussius) neglectus Tonnoir, 1921 & $\begin{array}{l}\text { Parrot [34]; Adler et al. [35]; Ristorcelli [36]; Hertig [37]; Hadjinico- } \\
\text { laou [38]; Pesson et al. [39]; Léger et al. [40]; Chaniotis et al. [41]; } \\
\text { Ivović et al. [42]; Ivović et al. [43]; Christodoulou et al. [44]; Alten } \\
\text { et al. [45] }\end{array}$ & Chania, Rethymno, Heraklion, Lasithi \\
\hline Ph. (Lar.) tobbi Adler \& Theodor, 1930 & Langeron [46]; Ivović et al. [42]; Christodoulou et al. [44] & Chania, Heraklion \\
\hline Ph. (Lar.) perfiliewi Parrot, 1930 & Pesson et al. [39]; Léger et al. [40]; Christodoulou et al. [44] & Rethymno, Heraklion, Lasithi \\
\hline Ph. (Adlerius) simici Nitzulescu, 1931 & $\begin{array}{l}\text { Parrot [34]; Adler et al. [35]; Ristorcelli [36]; Hertig [37]; Hadjinico- } \\
\text { laou [38]; Léger et al. [40]; Aransay et al. [47]; Christodoulou et al. } \\
\text { [44] }\end{array}$ & Chania, Rethymno, Heraklion, Lasithi \\
\hline Phlebotomus. (Adlerius) sp. & Léger et al. [40]; Christodoulou et al. [44] & Chania, Rethymno, Heraklion \\
\hline Ph. (Phlebotomus) papatasi Scopoli, 1786 & $\begin{array}{l}\text { Birt [50]; Blanc and Caminopetros [48]; Langeron [46]; Parrot [34]; } \\
\text { Adler et al. [35]; Ristorcelli [36]; Hertig [37]; Hadjinicolaou [38]; } \\
\text { Léger et al. [40]; Aransay et al. [47]; Ivović et al. [42]; Christodou- } \\
\text { lou et al. [44]; Alten et al. [45] }\end{array}$ & Chania, Rethymno, Heraklion, Lasithi \\
\hline Ph. (Paraphlebotomus) alexandri Sinton, 1928 & Aransay et al. [47]; Christodoulou et al. [44] & Chania, Heraklion \\
\hline Ph. (Par.) similis Artemiev \& Neronov, 1984 & $\begin{array}{l}\text { Blanc \& Caminopetros [48]; Langeron [46]; Parrot [34]; Adler et al. } \\
\text { [35]; Ristorcelli [36]; Hadjinicolaou [38]; Léger et al. [40]; Aransay } \\
\text { et al. [47]; Ivović et al. [42]; Christodoulou et al. [44]; Alten et al. } \\
\text { [45] }\end{array}$ & Chania, Rethymno, Heraklion, Lasithi \\
\hline Ph. (Transphlebotomus) mascittii Grassi, 1908 & $\begin{array}{l}\text { Parrot [34]; Adler et al. [35]; Ivović et al. [42]; Christodoulou et al. } \\
\text { [44] }\end{array}$ & Chania, Heraklion, Lasithi \\
\hline Ph. (Tra.) killicki Dvorak, Votypka \& Volf, 2015 & Kasap et al. [49] & Chania \\
\hline Se. (Sergentomyia) minuta Rondani, 1843 & $\begin{array}{l}\text { Langeron [46]; Parrot [34]; Adler et al. [35]; Hertig [37]; Hadjinico- } \\
\text { laou [38]; Léger et al. [40]; Aransay et al. [47]; Ivović et al. [42]; } \\
\text { Alten et al. [45] }\end{array}$ & Chania, Rethymno, Heraklion, Lasithi \\
\hline Se. (Ser.) dentata Sinton, 1933 & Ivović et al. [42] & Heraklion \\
\hline Sergentomyia sp. & Christodoulou et al. [44] & Chania, Rethymno, Heraklion, Lasithi \\
\hline
\end{tabular}


Table 4 Sand fly species found in the 2014 to 2019 samplings in Heraklion (Foinikia, Fodele), Lasithi (Xerokampos) and Chania (Agia Roumeli, Botanical Garden)

\begin{tabular}{|c|c|c|c|c|c|c|c|}
\hline Species & Foinikia (2018) & Fodele (2019) & $\begin{array}{l}\text { Xerokampos } \\
(2014)\end{array}$ & $\begin{array}{l}\text { Xerokampos } \\
(2019)\end{array}$ & $\begin{array}{l}\text { Agia Roumeli } \\
(2014)\end{array}$ & $\begin{array}{l}\text { Botanical Garden } \\
\text { (2019) }\end{array}$ & Total \\
\hline Ph. neglectus & 2 & 61 & 8 & 101 & 7 & 42 & 221 \\
\hline Ph. tobbi & 0 & 0 & 0 & 1 & 0 & 0 & 1 \\
\hline Ph. simici & 0 & 0 & 0 & 4 & 0 & 25 & 29 \\
\hline Ph. creticus n. sp. & 0 & 0 & 15 & 131 & 5 & 0 & 151 \\
\hline Ph. papatasi & 1 & 0 & 0 & 0 & 0 & 0 & 1 \\
\hline Ph. similis & 1 & 0 & 0 & 29 & 3 & 0 & 33 \\
\hline Ph. alexandri & 0 & 0 & 0 & 0 & 0 & 30 & 30 \\
\hline Ph. killicki & 0 & 0 & 0 & 1 & 0 & 4 & 5 \\
\hline Se.minuta & 29 & 0 & 0 & 32 & 0 & 76 & 137 \\
\hline Total & 33 & 61 & 23 & 299 & 15 & 177 & 608 \\
\hline
\end{tabular}

Table 5 Estimated total numbers of sand fly species reported both in publications and present samplings in Crete

\begin{tabular}{lll}
\hline Species & No. of specimens & Percentage \\
\hline Ph. neglectus & $\sim 20,000$ & $\sim 63.27$ \\
Ph. tobbi & 6 & $\sim 0.02$ \\
Ph. perfiliewi & 5 & $\sim 0.02$ \\
Ph. simici & $\sim 1300$ & $\sim 4.11$ \\
Phlebotomus (Adlerius) sp. & $\sim 35$ & $\sim 0.11$ \\
Ph. creticus n. sp. & 151 & $\sim 0.48$ \\
Ph. papatasi & $\sim 3000$ & $\sim 9.49$ \\
Ph. alexandri & $\sim 70$ & $\sim 0.22$ \\
Ph. similis & $\sim 5500$ & $\sim 17.40$ \\
Ph. mascittii & 30 & $\sim 0.09$ \\
Ph. killicki & 18 & $\sim 0.06$ \\
Se. minuta & $\sim 1000$ & $\sim 3.16$ \\
Se. dentata & 21 & $\sim 0.07$ \\
Sergentomyia sp. & 475 & $\sim 1.50$ \\
\hline
\end{tabular}

Moreover, they also showed a number of specific peaks, not shared by protein spectra of four Adlerius species in the reference database (Fig. 4b).

\section{Family Psychodidae Newman, 1834}

\section{Genus Phlebotomus Rondani \& Berté, 1840}

Phlebotomus creticus Antoniou, Depaquit \& Dvorak n. sp.

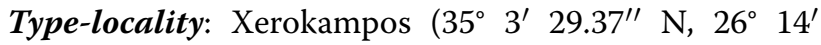
$27.14^{\prime \prime} \mathrm{E}$; altitude: $19 \mathrm{~m}$ above sea level), Greece Other localities: Fodele $\left(35^{\circ} 22^{\prime} 53.93^{\prime \prime} \mathrm{N}, 24^{\circ} 57^{\prime} 28.27^{\prime \prime}\right.$ $\mathrm{E}$; altitude: $48 \mathrm{~m}$ above sea level); Agia Roumeli ( $35^{\circ} 13^{\prime}$ $24.77^{\prime \prime} \mathrm{N}, 23^{\circ} 56^{\prime} 7.53^{\prime \prime} \mathrm{E}$; altitude: $14 \mathrm{~m}$ above sea level);

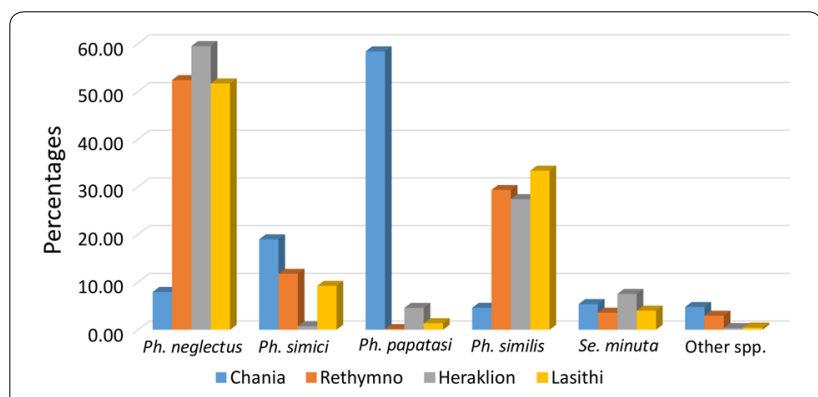

Fig. 2 Percentages of species collected per prefecture in both published literature and present samplings

Toplou Monastery $\left(35^{\circ} 13^{\prime} 16.69^{\prime \prime} \mathrm{N}, 26^{\circ} 12^{\prime} 51.99^{\prime \prime} \mathrm{E}\right.$; altitude: $159 \mathrm{~m}$ above sea level), Greece.

Type-material: The holotype male (accession no. ED10723) and five paratypes (3 males and 2 females, accession nos. ED10724, ED10725, ED10726 for male paratypes, accession nos. ED10727, ED10728 for female paratypes) have been deposited at the Laboratory of Entomology of the Muséum National d'Histoire Naturelle, Paris, France. Two paratypes (1 male and 1 female) have been deposited at the Museum of Natural History of London, UK, under the accession numbers NHMUK-ENT-2020-42. Two paratypes (1 male and 1 female) have been deposited at the Museum of Natural History of Heraklion, Crete, Greece, under the accession numbers NHMC.85.4.17830.1 (male paratype) and NHMC.85.4.17830.2 (females paratype).

Representative DNA sequences: GenBank accession numbers MT501628-MT501638.

ZooBank registration: To comply with the regulations set out in Article 8.5 of the amended 2012 version of the International Code of Zoological Nomenclature (ICZN) [33], details of the new species have been 
Table 6 Descriptive statistics for the measurements and counts for males of Ph. creticus n. sp.

\begin{tabular}{|c|c|c|c|c|}
\hline Character $^{a}$ & No. of specimens & Range & Mean & SD \\
\hline Flagellomere 1 (A III) & 45 & $285-406$ & 340 & 28.13 \\
\hline Flagellomere 2 (A IV) & 45 & $132-173$ & 150.8 & 11.52 \\
\hline Flagellomere 3 (A V) & 44 & $127-168$ & 148.4 & 10.47 \\
\hline Flagellomere 1 /flagellomere 2 + flagellomere 3 & 44 & $1.01-1.25$ & 1.13 & 0.05 \\
\hline Labrum & 50 & $237-310$ & 264.2 & 15.4 \\
\hline Flagellomere 1/labrum & 45 & $1.14-1.53$ & 1.29 & 0.09 \\
\hline Parameral sheath length & 54 & $178-219$ & 195.3 & 10.84 \\
\hline Distance between the tubercle and the top of the parameral sheath & 54 & $8-21$ & 15.3 & 2.49 \\
\hline Gonocoxite length & 53 & $345-451$ & 405.2 & 22.28 \\
\hline Beginning of the tuft of internal setae of the gonocoxite & 53 & $100-191$ & 148.4 & 17.7 \\
\hline$\%$ beginning vs gonocoxite length & 53 & $29-43$ & 36.5 & 2.85 \\
\hline Ending of the tuft of internal setae of the gonocoxite & 53 & $212-305$ & 260.3 & 19.01 \\
\hline$\%$ ending vs gonocoxite length & 53 & $60-68$ & 64.2 & 1.91 \\
\hline Tuft length & 53 & $92-129$ & 111.9 & 8.36 \\
\hline$\%$ tuft length vs gonocoxite length & 53 & $22-33$ & 27.7 & 2.26 \\
\hline Median tuft position vs gonocoxite & 53 & $45-55$ & 50.4 & 2.15 \\
\hline Sperm pump & 26 & $119-157$ & 133.2 & 9.61 \\
\hline Aedeagal ducts & 31 & $725-1082$ & 935.6 & 86.07 \\
\hline Aedeagal ducts/sperm pump & 26 & $6-8$ & 6.95 & 0.66 \\
\hline Number of setae & 50 & $54-85$ & 69.3 & 6.69 \\
\hline Gonocoxal internal setae area $\left(\mu^{2}\right)$ & 43 & $2553-4360$ & 3465 & 460.78 \\
\hline Mean $\mu^{2}$ per seta of the gonocoxal internal tuft & 43 & $40-64$ & 50.4 & 4.61 \\
\hline
\end{tabular}

$\mathrm{SD}$, standard deviation

a Measurements in $\mu \mathrm{m}$

Table 7 Descriptive statistics for the measurements and counts for females of Ph. creticus n. sp.

\begin{tabular}{lllll}
\hline Character $^{\text {a }}$ & $\begin{array}{l}\text { No. of } \\
\text { specimens }\end{array}$ & Range & Mean & SD \\
\hline Flagellomere 1 (A III) & 11 & $268-326$ & 298 & 16.92 \\
Flagellomere 2 (A IV) & 11 & $113-140$ & 125.45 & 7.96 \\
Flagellomere 3 (A V) & 11 & $108-141$ & 125.37 & 8.62 \\
$\begin{array}{l}\text { Flagellomere 1/flagel- } \\
\quad \text { lomere 2 + flagel- }\end{array}$ & 11 & $316-372$ & 338.87 & 17.20 \\
$\quad$ lomere 3 & 11 & & & \\
Labrum & 11 & $1.13-1.27$ & 1.19 & 0.04 \\
Flagellomere 1/labrum & $0.80-0.94$ & 0.88 & 0.05 \\
\hline
\end{tabular}

$\mathrm{SD}$, standard deviation

a Measurements in $\mu \mathrm{m}$

submitted to ZooBank. The Life Science Identifier (LSID) of the article is urn:lsid:zoobank.org:pub:D2A4798CA59B-4851-819F-DA238621A474. The LSID for the new name Phlebotomus creticus is urn:lsid:zoobank. org:act:218CBCD4-875D-48E1-B2B8-749D53E817DA. Etymology: The new species is named after the island where it has been discovered.

\section{Description}

Male [Based on 54 specimens. Counts and measurements indicated in the description are those of the holotype. More measurements for males are available in Table 6; Figs. 5, 6]. Total length $3.9 \mathrm{~mm}$. Head. Occiput with 2 lines of well individualized setae. Clypeus $171 \mu \mathrm{m}$ long, $92 \mu \mathrm{m}$ wide, with $c .19$ setae randomly distributed, targeting center of clypeus. Eyes $242 \mu \mathrm{m}$ high with $c .120$ facets. Interantennal suture incomplete. Interocular suture not reaching the interantennal suture. Flagellomeres: $\mathrm{f} 1(349 \mu \mathrm{m})$ longer than $\mathrm{f} 2(148 \mu \mathrm{m})+\mathrm{f} 3(149 \mu \mathrm{m})$. Internal and external ascoids implanted more or less at the same level on $\mathrm{f} 1$ to $\mathrm{f} 3$. Ascoids not reaching the next articulation. Ascoidal formula: 2/f1-f3 1/f4-f13 (=2/III-V 1/VI-XV). One distal papilla on flagellomeres f1, f2, f3, three sensillae on $\mathrm{f} 12$ and f13, five on f14. Palpi p1: $49 \mu \mathrm{m}$ long, p2: $173 \mu \mathrm{m}, \mathrm{p} 3: 192 \mu \mathrm{m}, \mathrm{p} 4: 160 \mu \mathrm{m}, \mathrm{p} 5: 400 \mu \mathrm{m}$. Palpal formula: 1, 4, 2, 3, 5. About 15 Newstead's sensilla present on $\mathrm{p} 3$ only; no sensilla on other palpal articles. One distal spiniform seta on p3, 12 setae on p4 and 26 setae on p5. Labrum-epipharynx $288 \mu \mathrm{m}$ long carrying long teeth at its top. Hypopharynx with 20 long apical teeth. Labial suture closed, narrow, in furca. Cibarium without teeth nor sclerotized area (= pigment patch) or 
Table 8 cytb sequence distances between and within (values in italic) the species analyzed under the Tamura-Nei model

\begin{tabular}{|c|c|c|c|c|c|c|c|c|c|}
\hline \multicolumn{2}{|c|}{ Species } & \multirow{2}{*}{$\frac{1}{0.008}$} & \multirow[t]{2}{*}{2} & \multirow[t]{2}{*}{3} & \multirow[t]{2}{*}{4} & \multirow[t]{2}{*}{5} & \multirow[t]{2}{*}{6} & \multirow[t]{2}{*}{7} & \multirow[t]{2}{*}{8} \\
\hline 1 & Ph. creticus n. sp. & & & & & & & & \\
\hline 2 & Ph. balcanicus & 0.044 & 0.006 & & & & & & \\
\hline 3 & Ph. simici & 0.111 & 0.107 & 0.002 & & & & & \\
\hline 4 & Ph. brevis & 0.137 & 0.115 & 0.064 & $--^{a}$ & & & & \\
\hline 5 & Ph.turanicus & 0.097 & 0.089 & 0.108 & 0.112 & $--^{a}$ & & & \\
\hline 6 & Ph. halepensis & 0.109 & 0.077 & 0.140 & 0.113 & 0.103 & 0.011 & & \\
\hline 7 & Ph. chinensis & 0.124 & 0.128 & 0.130 & 0.134 & 0.138 & 0.168 & 0.011 & \\
\hline 8 & Ph. perfiliewi & 0.129 & 0.137 & 0.152 & 0.182 & 0.141 & 0.188 & 0.159 & $-^{a}$ \\
\hline
\end{tabular}

a Only one specimen sequenced

sclerotized arch. Pharynx with an armature consisting of long teeth directed laterally or towards center. Cervix with 3 lateral cervical sensillae and 2 median sensillae on each side. Thorax. Sclerites pale coloured. One postalar seta present on the mesonotum. Paratergital seta absent. A group of four proepimeral setae. Upper anepisiternal seta, lower anapisternal seta, anepimeral seta, metaepisternal seta and metaepimeral seta absent. Setae present on the anterior region of the katepisternum. Metafurca mounted in lateral view on all specimens. Vertical arms long, probably separate; horizontal arms long. Wings. Length: $2370 \mu \mathrm{m}$; width: $715 \mu \mathrm{m}$; $\mathrm{r} 5: 1537 \mu \mathrm{m}$; $\alpha$ (r2): $475 \mu \mathrm{m} ; \beta(\mathrm{r} 2+3): 309 \mu \mathrm{m} ; \gamma(\mathrm{r} 2+3+4): 373 \mu \mathrm{m}$; $\delta: 120 \mu \mathrm{m} ; \pi: 90 \mu \mathrm{m} ; \varepsilon(\mathrm{r} 3): 692 \mu \mathrm{m} ; \theta(\mathrm{r} 4): 1091 \mu \mathrm{m}$; width/ $\gamma$ : 1.92. Legs. Anterior leg: coxa: $337 \mu \mathrm{m}$; femur: $855 \mu \mathrm{m}$; tibia: $1021 \mu \mathrm{m}$; tarsomere i: $620 \mu \mathrm{m}$; sum of tii, tiii, tiv, tv: $770 \mu \mathrm{m}$. Median leg: coxa: $353 \mu \mathrm{m}$; femur: $870 \mu \mathrm{m}$; tibia: $1218 \mu \mathrm{m}$; tarsomere i: $704 \mu \mathrm{m}$; sum of tii, tiii, tiv, tv: $810 \mu \mathrm{m}$. Posterior leg: coxa: $394 \mu \mathrm{m}$; femur: $1005 \mu \mathrm{m}$; tibia: $1558 \mu \mathrm{m}$; tarsomere i: $887 \mu \mathrm{m}$; sum of tii, tiii, tiv, tv: $944 \mu \mathrm{m}$. Spines on the metafemur absent. Metatarsomere iii with 4 verticils including broad and thin spines. Abdomen. Setae randomly implantated on tergites II to V. Two papillae with hair present on tergites III to VI. Gonocoxite $441 \mu \mathrm{m}$ long. Sclerotized band in the ventral margin abent; process absent; a median cluster of 71 setae on the internal side present. Gonostyle $204 \mu \mathrm{m}$ long, with 5 spines: 2 distal spines implanted at the same level; 3 median spines: 1 ventral implanted on narrow tubercle and 2 dorsal implanted on wide tubercle. Parameres $462 \mu \mathrm{m}$ long, simple, rounded at apex, with setae occupying inner face of distal half. Parameral sheath straight, $203 \mu \mathrm{m}$ long, with very shallow subterminal tubercle $20 \mu \mathrm{m}$ to the top. Aedeagal ducts $927 \mu \mathrm{m}$ long, isodiametric and pointed at their tops. Sperm pump $145 \mu \mathrm{m}$ long. Ejaculatory apodeme $119 \mu \mathrm{m}$ long. Aedeagal ducts/sperm pump ratio: 6.39. Epandrial lobes slightly longer than gonocoxites, length $468 \mu \mathrm{m}$.
Female [Based on 11 specimens. Counts and measurements indicated in the following description are those of the paratype labelled Crete IT8 with some exceptions which are indicated. More measurements for females available in Table 7; Fig. 7]. Total length of the paratype Crete IT14: $3.6 \mathrm{~mm}$ long. Head. Occiput with two narrow lines of well individualized setae. Clypeus $135 \mu \mathrm{m}$ long, $103 \mu \mathrm{m}$ wide, with 20 setae randomly distributed, targeting the center of the anterior part of the clypeus. Eyes $193 \mu \mathrm{m}$ high with about 90 facets. Interantennal suture incomplete. Interocular suture not reaching the interantennal one. Flagellomeres: $\mathrm{f} 1(208 \mu \mathrm{m})$ longer than $\mathrm{f} 2(98 \mu \mathrm{m})+\mathrm{f} 3(100 \mu \mathrm{m})$. Internal and external ascoids implanted more or less at the same level on $\mathrm{f} 1$ to $\mathrm{f} 3$. Ascoids not reaching the next articulation. Ascoidal formula: 2/f1-f13 (=2/III-XV). One papilla on flagellomeres $\mathrm{f} 1, \mathrm{f} 2, \mathrm{f} 3$, three sensillae on $\mathrm{f} 12$ and $\mathrm{f} 13$, five on $\mathrm{f} 14$. Palpi p1: $40 \mu \mathrm{m}$ long, p2: $153 \mu \mathrm{m}, \mathrm{p} 3: 160 \mu \mathrm{m}, \mathrm{p} 4: 130 \mu \mathrm{m}, \mathrm{p} 5$ : $315 \mu \mathrm{m}$. Palpal formula: 1, 4, 2, 3, 5. Presence of about 15 Newstead's sensilla on p3. Absence of Newstead's sensilla on the other palpal articles. One distal spiniform setae on p3,7 on p4 and 31 on p5. Labrum-Epipharynx $268 \mu \mathrm{m}$ long. $\mathrm{f} 1 / \mathrm{E}=0.78$. Hypopharynx with about 15 distal long teeth on each side. Maxillary lacinia exhibiting 4 external and 20 internal teeth. Labial suture closed, narrow, in furca. Cibarium without teeth nor sclerotized area $(=$ pigment patch) or sclerotised arch. Pharynx with a triangular armature consisting of elongated teeth directed towards the center. Cervix with two lateral cervical sensillae and two median ones on each side. Thorax. Pale coloured sclerites. Presence of one post-alar seta on the mesonotum. Absence of paratergital seta. A group of six proepimeral setae. Absence of upper anepisiternal seta. Absence of lower anapisternal seta. Absence of anepimeral seta. Absence of metaepisternal seta. Absence of metaepimeral seta. Presence of setae in the anterior region of the katepisternum. Metafurca mounted in lateral view on all specimens. Long vertical arms probably separate. Long horizontal arms.738. Wings. Length $=2173 \mu \mathrm{m}$, 


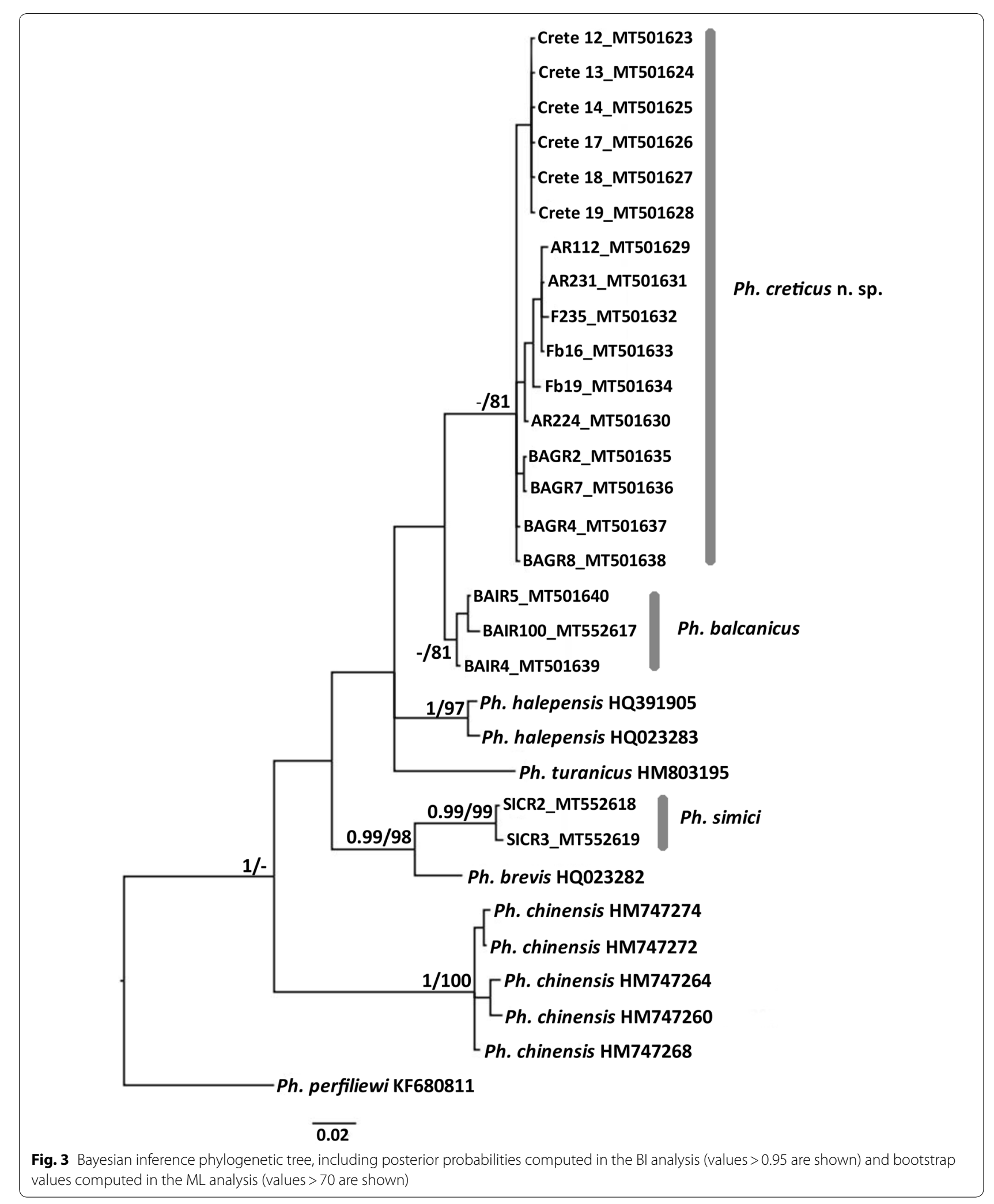




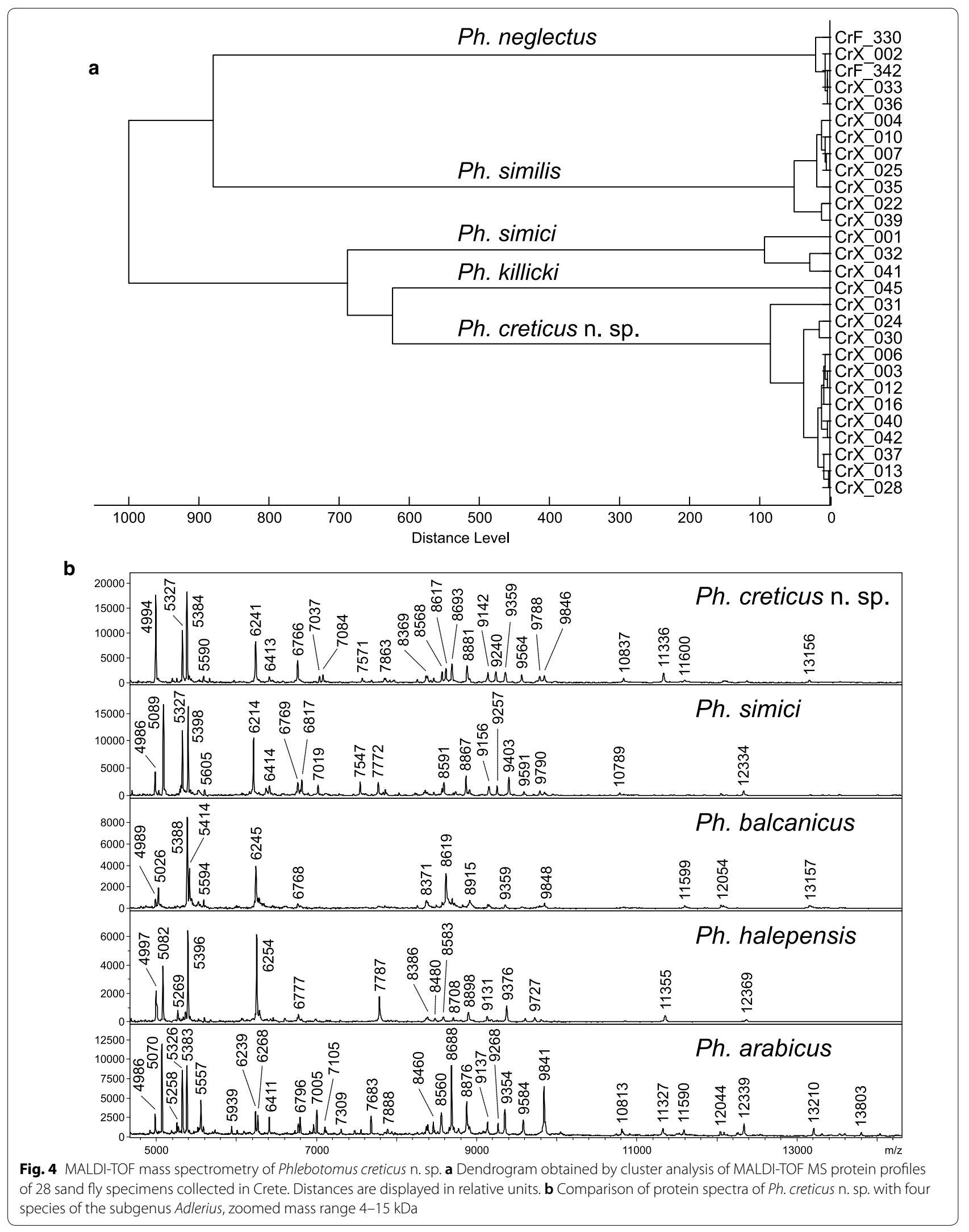




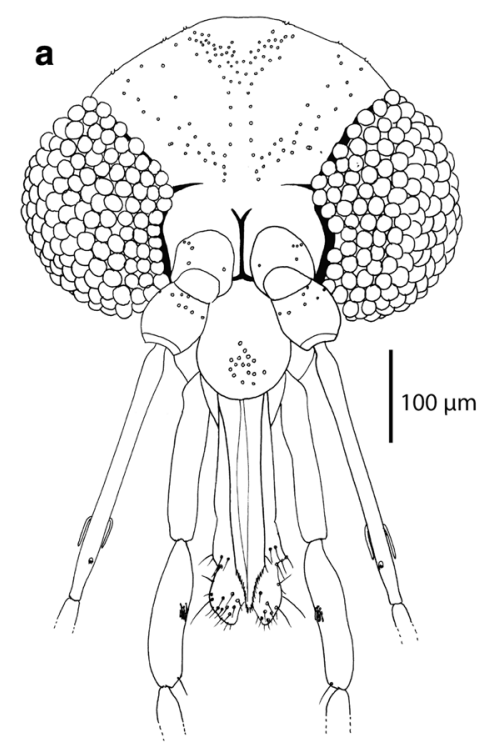

b

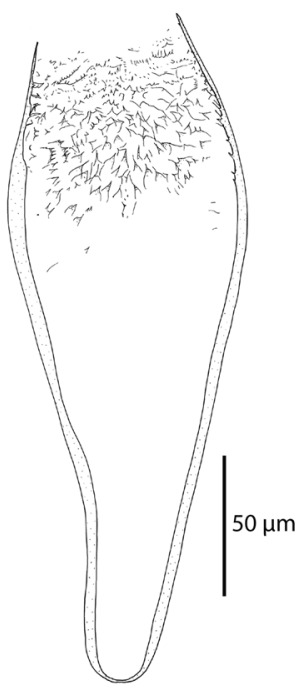

\section{d}
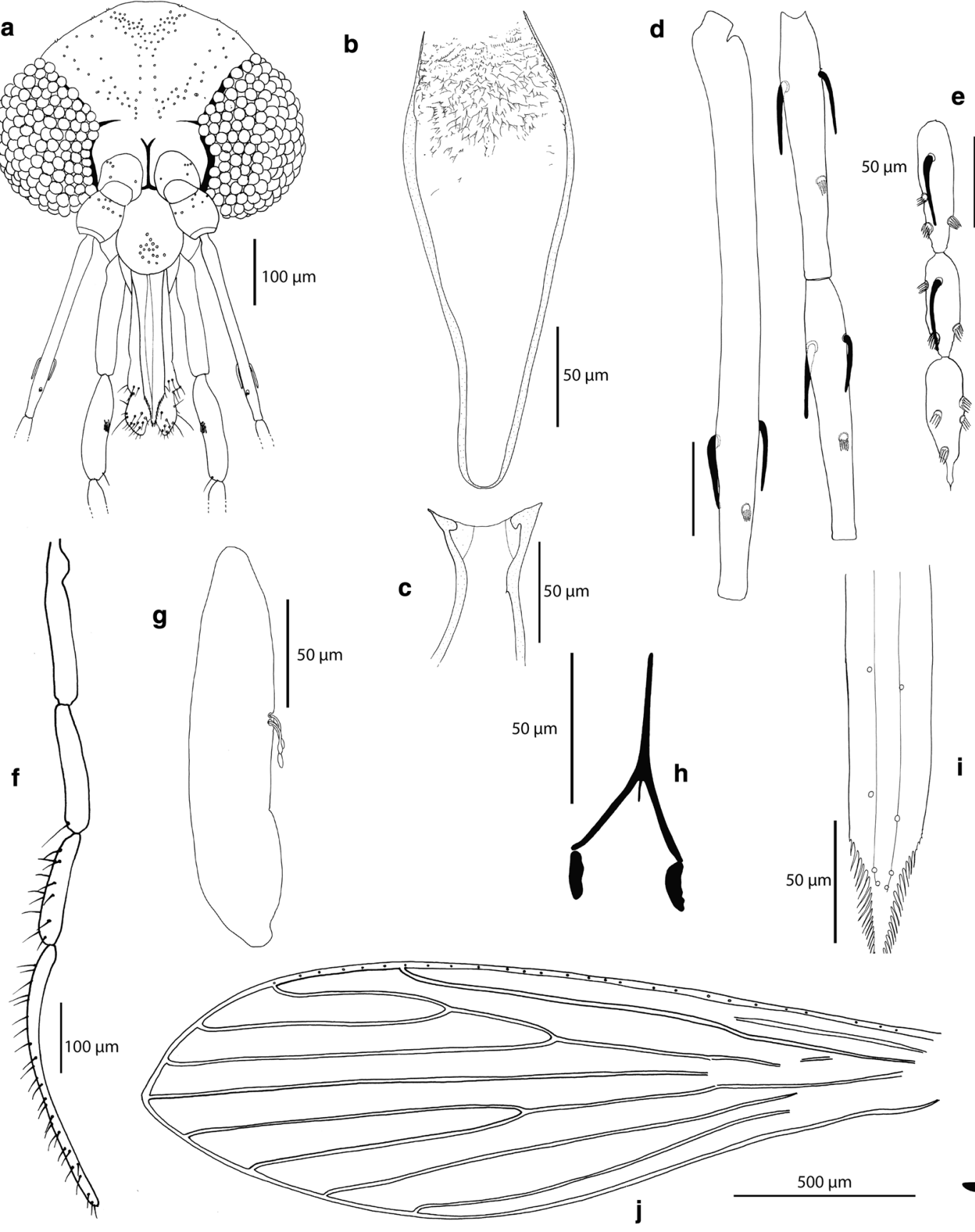

Ð)

Fig. 5 Phlebotomus creticus n. sp. male. a Head. b Pharynx. c Cibarium. d Flagellomeres 1, 2 and 3. e Flagellomeres 12, 13 and 14. f Palp. g Third palpal article. $\mathbf{h}$ Labial furca. i Labrum. $\mathbf{j}$ Wing

width $=578 \mu \mathrm{m}, \quad \mathrm{r} 5=1424 \mu \mathrm{m}, \alpha(\mathrm{r} 2)=431 \mu \mathrm{m}, \quad \beta$ $(\mathrm{r} 2+3)=225 \mu \mathrm{m}, \gamma(\mathrm{r} 2+3+4)=398 \mu \mathrm{m}, \delta=101 \mu \mathrm{m}$, $\pi=61 \mu \mathrm{m} . \varepsilon(\mathrm{r} 3)=612 \mu \mathrm{m}, \theta(\mathrm{r} 4)=944 \mu \mathrm{m}$. Width / $\gamma=1.70$. Anterior leg: $\operatorname{coxa}=273 \mu \mathrm{m}$; femur $=811 \mu \mathrm{m}$; tibia $=971 \mu \mathrm{m}$; tarsomere $\mathrm{i}=595 \mu \mathrm{m}$; sum of tii, tiii, tiv, $\mathrm{tv}=728 \mu \mathrm{m}$. Median leg: $\operatorname{coxa}=328 \mu \mathrm{m}$; femur $=817 \mu \mathrm{m}$; tibia $=1150 \mu \mathrm{m}$; tarsomere $\mathrm{i}=686 \mu \mathrm{m}$; sum of tii, tiii, tiv, $t v=775 \mu \mathrm{m}$. Posterior leg: $\operatorname{coxa}=383 \mu \mathrm{m}$; femur $=890 \mu \mathrm{m}$; tibia $=1522 \mu \mathrm{m}$; tarsomere $\mathrm{i}=848 \mu \mathrm{m}$; sum of tii, tiii, tiv, tv $=876 \mu \mathrm{m}$. Absence of spines on the metafemur. Metatarsomere iii with a distal verticil and a median one, including broad and thin spines. Abdomen. 

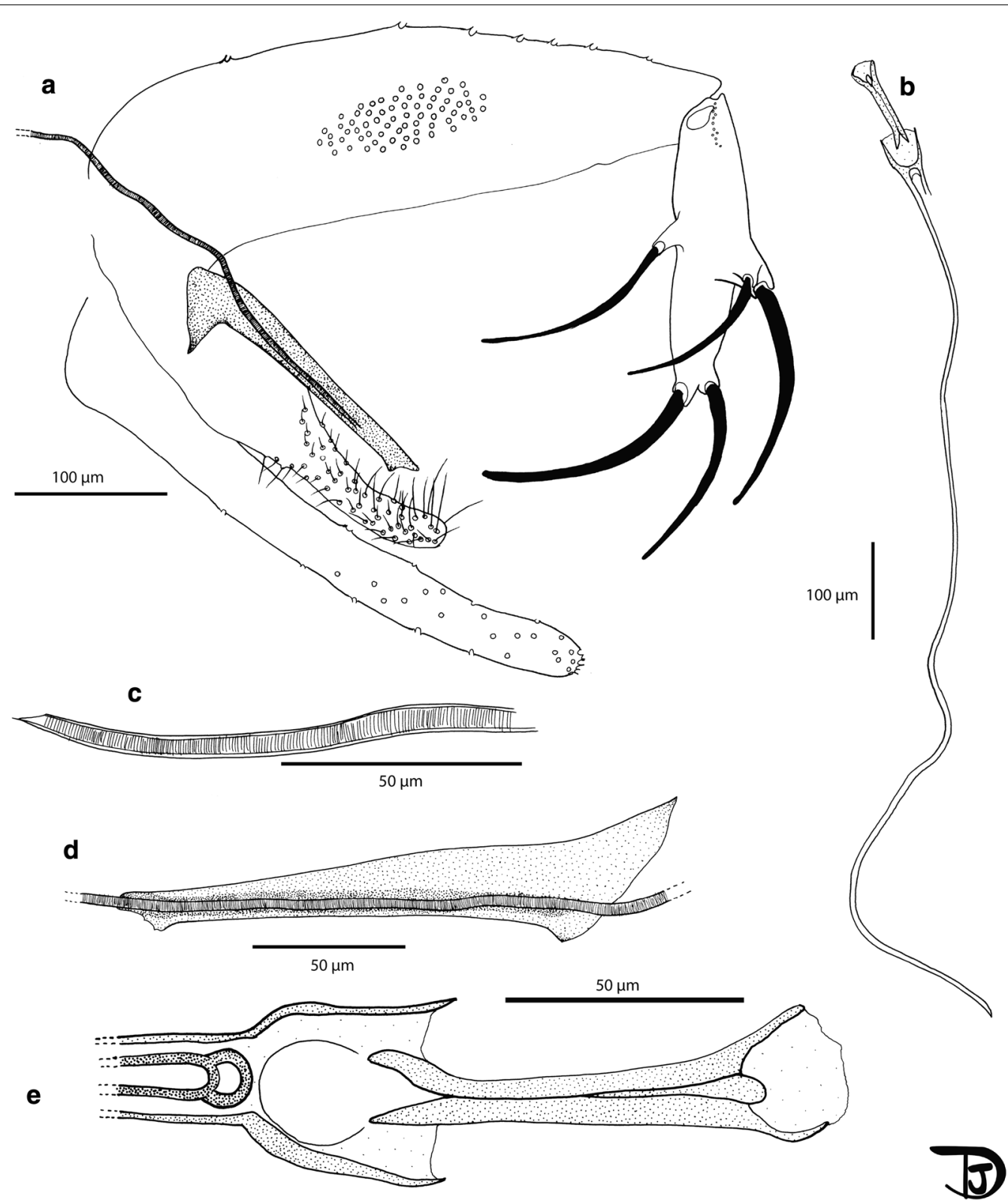

Fig. 6 Phlebotomus creticus n. sp. male. a Genitalia. b Sperm pump and aedeagal ducts. c Top of the aedeagal ducts. d Parameral sheath. e Sperm pump

Setae randomly implantated on tergites II to V. Presence of papillae on tergites III to VII. Genitalia. Presence of about $8+1$ setae on tergite VIII. Lack of protuberance on tergite IX. Spermathecae incompletely segmented. Basal part of the ducts wide with thick walls. Those of the paratype Crete IT8 have been collapsed during the mounting. The measurements indicated are those of the paratype crete7 mounted in Marc-André to be observed, measured and drawn before final process and mounting. Length of the ducts: $600 \mu \mathrm{m}$ (including $100 \mu \mathrm{m}$ of the wide basal part and $500 \mu \mathrm{m}$ of the narrow ducts); length of the body: $100 \mu \mathrm{m}$. Genital fork $192 \mu \mathrm{m}$ long. Cerci rounded at their top, $178 \mu \mathrm{m}$ long. No seta observed on the sternite X.

\section{Differential diagnosis}

In males, number of ascoids usually 2/f1-f3, 1/f4-f13, a range of 54-85 setae on the gonocoxal internal tuft equally distributed between the proximal and distal halves of the gonocoxite. 
Microhabitat preferences of Ph. creticus n. sp.

At Fodele, Ph. creticus n. sp. was captured in four CDC light traps placed near or in cave entrances, facing southeast and south. The vegetation around was rich. Mainly chicken, rats and lizards dwell around the traps. No specimens of Ph. creticus n. sp. were collected by sticky traps. At Xerokampos, the species was captured in two traps placed at the entrance of two shallow caves facing southeast, at $200 \mathrm{~m}$ distance from the shore. The vegetation around the caves was composed of phrygana, biotope typical for island of Crete. At Agia Roumeli the species was captured in two traps placed at the entrance of two limestone rock caves, one facing east and the other facing south, in a separate beach located west of Agia Roumeli, just a few meters from the sea. The vegetation above the caves was composed from sparse phrygana. In Toplou Monastery, it was trapped in caves along the wall just before the Monastery.

\section{Discussion}

The island of Crete is an important and long-time active region of leishmaniases transmission and still provides ample numbers of human cases annually. As sand flies are the only proven vectors of these diseases in the Mediterranean basin, there is a need for sustained monitoring of the sand fly fauna and its role in Leishmania transmission. While studied for a long time, there are surprising new findings regarding the presence of sand fly species as documented by a recent description of Phlebotomus (Transphlebotomus) killicki Dvorak, Votypka \& Volf, 2015 in the localities at the southern coast of the island [49]. The results of the presented study reveal that there is still more to discover.

Published data as well as new results from the present sampling (2014-2019) show that the most widespread and abundant species in Crete is Ph. neglectus, accounting for more than $60 \%$ of the recorded sand fly specimens. It is a proven vector of $L$. infantum in Greece, several other Balkan countries and the western part of Turkey [1]. Its abundance in all studied areas of Crete apparently contributes to the geographical distribution of VL cases throughout the island and as other species of the subgenus Larroussius are markedly scarce, we may conclude that Ph. neglectus remains a sole vector of the disease. The second most common and abundant species on the island is Phlebotomus similis. It is morphologically similar and phylogenetically closely related to $P h$. sergenti $[51,52]$ and is regarded as a suspected vector of $L$. tropica in regions where Ph. sergenti is not present, including Crete [2]. The fact that Ph. similis was found in all foci of human CL further fosters the considerations of this species as a yet unproven vector of L. tropica in the island. Phlebotomus papatasi is a proven vector of $L$. major in the Middle East and Northern Africa and it is known to be responsible for the phlebovirus infections in the Old World $[53,54]$ including Crete [55]. However, L. major, the causative agent of zoonotic cutaneous leishmaniasis, does not circulate in Crete, probably due to absence of suitable reservoir species (gerbils). Vectorial competence of Sergentomyia spp. to mammalian diseases is still controversial and experimental studies that would conclusively test it are scarce [56] despite growing circumstantial evidence that suggest incrimination of some species in the transmission of human leishmaniasis and phleboviruses [57]. Of two Sergentomyia species previously recorded from Crete, only Se. minuta was found in this study. Bloodmeal analyses of population in southern Portugal recently demonstrated that this widely distributed Mediterranean species may be at least partially anthropophilic and the detection of Leishmania DNA in specimens from the same area emphasizes the need of further studies about the role of Sergentomyia species in leishmaniases transmission cycles [58].

Adlerius specimens collected at different sites throughout the island during 2014-2019 did not meet the criteria of any known species and exhibited unique morphological characters. Moreover, obtained sequences of cytb, when compared with sequences of species within the subgenus Adlerius available in public databases, were substantially different. That led us to the conclusion that the collected specimens represent a new species. The identity of this new species is based on a detailed morphological analysis of decisive characters that is further supported by sequencing of $c y t b$ gene, a widely used genetic marker, and for the first time in a description of a new sand fly species, also by comparison of speciesspecific protein spectra acquired by MALDI-TOF mass spectrometry.

According to Artemiev [10], the subgenus Adlerius includes 17 described and two undescribed species. While the females mostly appear to be undistinguishable, the main characters to identify the males of this subgenus are the antennal formula, used in all available identification keys [10, 11,59] and the number of setae of the internal tuft of the gonocoxite as well as the position of this tuft on the gonocoxite.

Considering that the number of ascoids in Ph. creticus n. sp. was usually 2/f1-f3, 1/f4-f13, the most similar species are Ph. angustus Artemiev, 1978, Ph. balcanicus, Ph. comatus Artemiev, 1978, Ph. kyreniae Theodor, 1958, Ph. salangensis Artemiev, 1978 and Ph. zulfagarensis Artemiev, 1978 [10]. However, this parameter varied not only in Ph. creticus n. sp., its infraspecific variation is known also in other sand fly species. Therefore, the antennal 


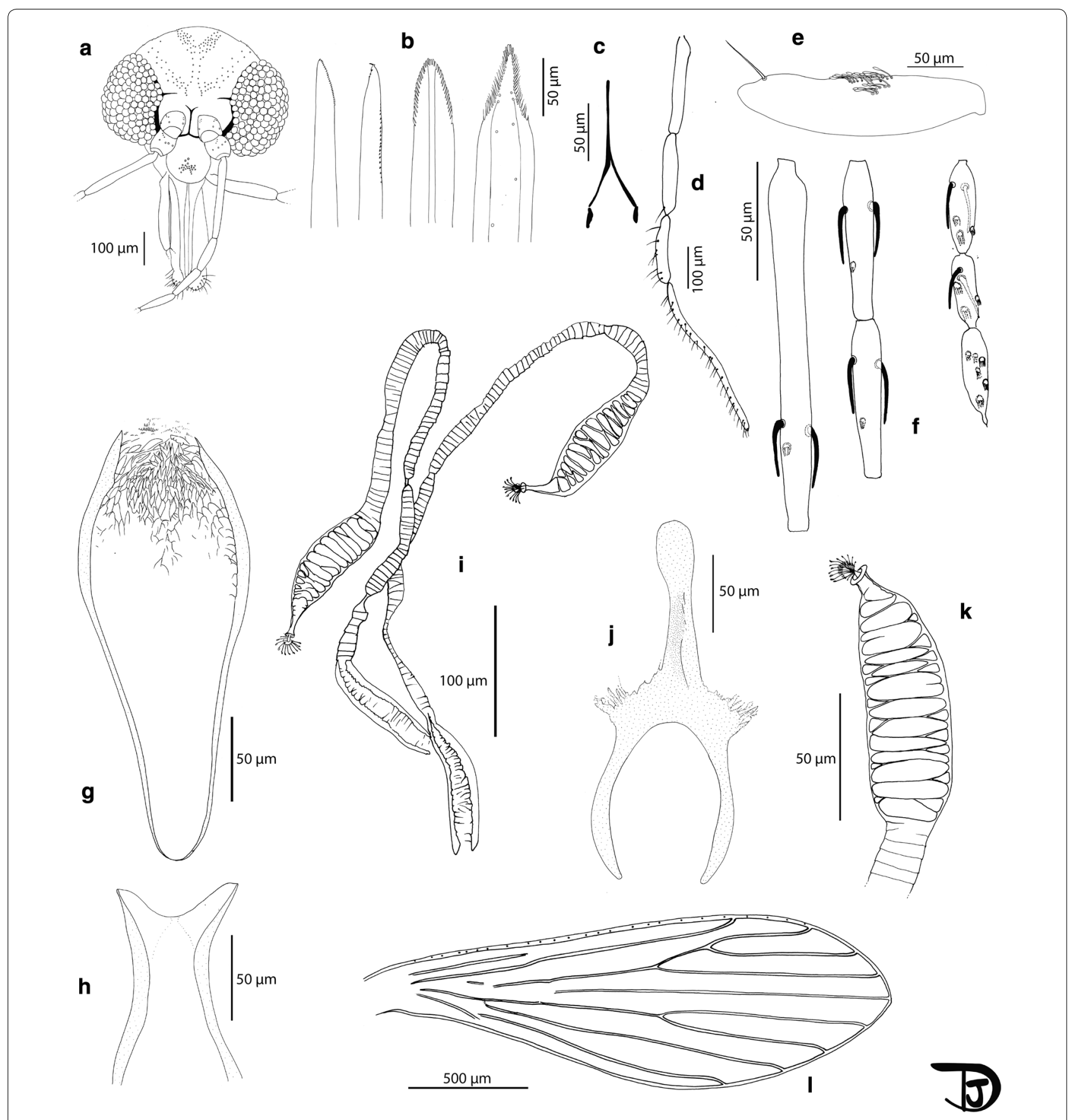

Fig. 7 Phlebotomus creticus n. sp. female. a Head. b Mouth parts (mandible, maxilla, hypopharynx and labrum, respectively). c labial furca. d Palp. e Third palpal article. f Flagellomeres 1, 2, 3, 12, 13 and 14; G pharynx. h Cibarium. i Spermathecae. $\mathbf{j}$ Genital fork. $\mathbf{k}$ Body of the spermathecae. I Wing

formula may not be alone a useful parameter for species identification of Adlerius sand flies.

Phlebotomus creticus $\mathrm{n}$. sp. exhibits a range of 54-85 setae on the gonocoxal internal tuft (mean: 69). This count excludes the identification of Ph. balcanicus (92130 setae after Artemiev [10] and more than 100 in the original description [reference number]), Ph. comatus (126-220 setae) and Ph. kyreniae (30-40 setae). There is an overlap related to this number of setae for Ph. creticus n. sp. and Ph. angustus (35-69 setae), Ph. salangensis (40-85 setae) and Ph. zulfagarensis (66-72 setae). However, these three species exhibit group of setae which is completely or at $90 \%$ in the proximal half of the gonocoxite [10] whereas that of Ph. creticus n. sp. is equally distributed between the proximal and distal halves of the gonocoxite (Table 6, Fig. 1). Moreover, all three species 
are known to be distributed in Asia, in regions very distant from Crete. In contrast, in Ph. balcanicus the hair group is located mainly on the basal half of the coxite [12]. Consequently, regarding the typological systematics, there is substantial evidence to consider Ph. creticus as a distinct species.

Phlebotomus creticus n. sp. was recorded at different localities at both northern and southern coast of Crete divided by a mountain range of a considerable height, which further supports a long presence rather than a recent introduction. However, it is probably not a common species. Phlebotomus creticus n. sp. was not caught on sticky traps placed in the openings of holes on natural or manmade walls and ground. We assume that it preferentially rests inside shallow caves in limestone rocks. In such specific biotopes it could be a dominant species as demonstrated in Xerokampos. Its feeding preferences should be investigated, although wildlife hosts may be expected (mice, birds and possibly lizards). Beside this newly described species, Ph. simici of the same subgenus that had been reported from Crete in the past, was still recorded in this study, occurring even sympatrically at the type-locality Xerokampos. We may speculate that in previous entomological surveys, some of the specimens identified as Ph. simici or unidentified Adlerius sp. may be attributed to the newly described Ph. creticus $\mathrm{n}$. sp.

The results of the molecular analyses support the description of a new species. Phylogenetic analyses of the cytochrome $b$ gene, a mitochondrial marker widely used in phylogenetic studies of many insect groups including sand flies, strongly grouped all analyzed specimens of Ph. creticus n. sp. in a distinct monophyletic clade. This genetic marker was chosen as it provides the best coverage of the species within the subgenus Adlerius. Unfortunately, no sequences of any genetic marker are so far available for some species of the subgenus, including the three species with overlapping numbers of setae on the gonocoxal internal tuft. Genetic distance values obtained for Ph. creticus n. sp. and other compared Adlerius species are comparable with the distances recorded previously for other sand fly species, as shown by studies of morphologically- as well as genetically distinct species of the subgenera Larroussius and Phlebotomus [60] or Madaphlebotomus [9]. Moreover, MALDI-TOF protein profiling demonstrated that all processed specimens of $P h$. creticus n. sp. produced unique, reproducible and species-specific profiles that clearly differentiate them from other species outside and within the subgenus Adlerius. This method of mass spectrometry has recently become a popular tool for species identification of various organisms including arthropod vectors as it is simple, rapid and cost-effective [61]. Here, we demonstrated for the first time that it can also successfully complement traditional morphological approach and established DNA-based molecular taxonomy in the process of revealing yet unrecognized sand fly species.

Our recent findings urge the need for a revision of the subgenus Adlerius using both morphological and molecular approaches. Species boundaries are not well defined and the vicariance of this group probably occurred recently as for other groups of phlebotomine sand flies such as Phlebotomus, Larroussius or Paraphlebotomus $[16,18,62]$.

\section{Conclusions}

In this study we present a review of sand fly species recorded in the past and at present in Crete, an island with ongoing transmission of two Leishmania species due to the presence of competent sand fly vectors. The importance of this research is highlighted by the geographical position of the island and the current possibility of accidental introduction of more Leishmania species due to human migration and other activities. According to our findings, 10 Phlebotomus spp. and 2 Sergentomyia spp. were recorded, with the most common and abundant species being Ph. neglectus. We may assume that the findings of Ph. mascittii reported prior to the description of Ph. killicki may be attributed to the latter species. We identify and describe a new species Phlebotomus (Adlerius) creticus $\mathrm{n}$. $\mathrm{sp}$. from various localities in Crete. Its identification is based on morphological characters of the male genitalia that particularly differentiate it from related species of the subgenus Adlerius. The identity of the newly described species was confirmed by two molecular approaches (MALDI-TOF protein profiling and $c y t b$ sequence analysis). As there is no data on the vectorial competence and capacity of this new species, its potential role in the autochtonous transmission cycles of Leishmania shall be further studied.

\section{Abbreviations}

BI: Bayesian inference; BIC: Bayesian information criterion; CL: Cutaneous leishmaniasis; cytb: Cytochrome b gene; MALDI-TOF MS: Matrix-assisted laser desorption/ionization time-o-flight mass spectrometry; ML: Maximum likelihood; PCR: Polymerase chain reaction; VL: Visceral leishmaniasis.

\section{Acknowledgements}

We would like to thank Elif Konuksal for his help during the fieldwork in Fodele and Thord Fransson and Dimitris Chatzidakis for their help during the fieldwork in Xerokampos. We would also like to thank Rea L. Antoniou-Kourounioti for the statistical analyzes of the morphological characters and Vasiliki Christodoulou for preparing a map of Crete used in the graphical abstract to depict collection sites of Ph. creticus n. sp.

\section{Authors' contributions}

NT, VD, JD, CP, ED, PV and MaA carried out specimen collection and identification. JD provided camera lucida drawings. VD, PH, ED, JD and MoA carried out molecular analyses. NT, VD, PH, JD, PV and MaA did data interpretation. VD, $C P, J D, P V$ and MaA did project planning. VD, PH, CP, JD, MoA, PV and MaA prepared the manuscript. All authors read and approved the final manuscript. 


\section{Funding}

This research was supported by the projects BIOCEV CZ.1.05/1.1.00/02.0109 and CePaViP CZ.02.1.01/0.0/0.0/16_019/0000759 from the European Regional Development Fund. Additional support from the Czech Infrastructure for Integrative Structural Biology (LM2015043 funded by MEYS CR) is gratefully acknowledged. Thanks are due to Nicole Léger, Bernard Pesson, Geneviève Madulo-Leblond, Byron Papadopoulos and Hubert Ferté for collecting the specimens from Toplou Monastery and to Bulent Alten for their support and advice throughout this work.

\section{Availability of data and materials}

The datasets supporting the conclusions of this article are included within the article and its additional files. The holotype and paratypes of a newly described species Phlebotomus creticus n. sp.were deposited in three repositories as described above. The newly generated sequences were deposited in the GenBank database under the accession numbers MT501623-MT501638.

\section{Ethics approval and consent to participate}

The study involved collecting adult sand flies in the open field, from domestic animal shelters and human houses by traps. Local or regional ethics committee approval was not required for such work. Setting the traps near houses or in fields was performed with informed consent and cooperation of the owners and the local authorities.

\section{Consent for publication}

Not applicable.

\section{Competing interests}

The authors declare that they have no competing interests.

\begin{abstract}
Author details
1 Department of Parasitology, Faculty of Science, Charles University, Prague, Czech Republic. ${ }^{2}$ Laboratory of Clinical Bacteriology Parasitology Zoonoses and Geographical Medicine, Faculty of Medicine, University of Crete, Heraklion, Greece. ${ }^{3}$ Département de Parasitologie-Mycologie, Hôpital Avicenne AP-HP, Bobigny, France. ${ }^{4}$ BioCeV - Institute of Microbiology, The Czech Academy of Sciences, Vestec, Czech Republic. "FEA7510 "ESCAPE", USC ANSES "VECPAR", Faculté de Pharmacie, Université de Reims Champagne-Ardenne, 51, rue Cognacq-Jay, 51096 Reims cedex, Reims, France.
\end{abstract}

Received: 9 March 2020 Accepted: 11 September 2020 Published online: 04 November 2020

\section{References}

1. Maroli M, Feliciangeli MD, Bichaud L, Charrel RN, Gradoni L. Phlebotomine sandflies and the spreading of leishmaniases and other diseases of public health concern. Med Vet Entomol. 2013;27:123-47.

2. Antoniou M, Gramiccia M, Molina R, Dvorak V, Volf P. The role of indigenous phlebotomine sandflies and mammals in the spreading of leishmaniasis agents in the Mediterranean region. Euro Surveill. 2013;18:20540.

3. Svobodova M, Votypka J, Peckova J, Dvorak V, Nasereddin A, Baneth G, et al. Distinct transmission cycles of Leishmania tropica in 2 adjacent foci, Northern Israel. Emerg Infect Dis. 2006;12:1860-8.

4. Jacobson RL. Leishmania tropica (Kinetoplastida: Trypanosomatidae) - a perplexing parasite. Folia Parasitol. 2003;50:241-50.

5. Antoniou M, Haralambous C, Mazeris A, Pratlong F, Dedet J-P, Soteriadou K. Leishmania donovani causing visceral or cutaneous leishmaniasis in Europe: Cyprus evidence is an alarm call. Lancet Infect Dis. 2008;8:6-7.

6. Ntais P, Christodoulou V, Tsirigotakis N, Dokianakis E, Dedet J-P, Pratlong $\mathrm{F}$, et al. Will the introduction of Leishmania tropica MON-58, in the island of Crete, lead to the settlement and spread of this rare zymodeme? Acta Trop. 2014;132:125-30.

7. Dvorak V, Shaw J, Volf P. Parasite biology: the vectors. In: Bruschi F, Gradoni L, editors. The leishmaniases: old neglected tropical diseases. Cham: Springer International Publishing; 2018. p. 31-77.

8. Moher D, Shamseer L, Clarke M, Ghersi D, Liberati A, Petticrew M, et al. Preferred reporting items for systematic review and meta-analysis protocols (PRISMA-P) 2015 statement. Syst Rev. 2015;4:1.
9. Blavier A, Laroche L, Randrianambinintsoa FJ, Lucas V, Gantier J-C, Léger N, et al. Phlebotomine sandflies (Diptera, Psychodidae) from the Ankarana tsingy of northern Madagascar: inventory and description of new taxa. Parasite. 2019;26:38.

10. Artemiev MM. A revision of sandflies of the subgenus Adlerius (Diptera, Phlebotominae, Phlebotomus). Zool Zhurnal. 1980;59:1177-92.

11. Lewis DJ. A taxonomic review of the genus Phlebotomus (Diptera: Psychodidae). Bull Br Mus Nat Hist (Ent). 1982;45:121-209.

12. Léger N, Pesson B, Madulo-Leblond G. Les phlébotomes de Grèce. Biol Gallo-hell. 1986;11:165-91.

13. Killick-Kendrick R, Tang Y, Killick-Kendrick M, Sang DK, Sirdar MK, Ke L, et al. The identification of female sandflies of the subgenus Larroussius by the morphology of the spermathecal ducts. Parassitologia. 1991;33:335-47.

14. Depaquit J, Léger N, Ferté H, Rioux JA, Gantier JC, Michaelides A, et al. Les Phlébotomes de lîle de Chypre III. Inventaire faunistique. arasite. 2001;8:11-20.

15. Galati EAB, Galvis-Ovallos F, Lawyer P, Léger N, Depaquit J. An illustrated guide for characters and terminology used in descriptions of Phlebotominae (Diptera, Psychodidae). Parasite. 2017;24:26.

16. Esseghir S, Ready PD, Killick-Kendrick R, Ben-Ismail R. Mitochondrial haplotypes and phylogeography of Phlebotomus vectors of Leishmania major. Insect Mol Biol. 1997;6:211-25.

17. Parvizi P, Naddaf SR, AlaeeNovin E. Molecular typing and phylogenetic analysis of some species belonging to Phlebotomus (Larroussius) and Phlebotomus (Adlerius) subgenera (Diptera: Psychodidae) from two locations in Iran. Iran J Arthropod Borne Dis. 2010;4:1-10.

18. Mahamdallie SS, Pesson B, Ready PD. Multiple genetic divergences and population expansions of a Mediterranean sandfly, Phlebotomus ariasi, in Europe during the Pleistocene glacial cycles. Heredity. 2011;106:714-26.

19. Krüger A, Strüven L, Post RJ, Faulde M. The sandflies (Diptera: Psychodidae, Phlebotominae) in military camps in northern Afghanistan (2007-2009), as identified by morphology and DNA 'barcoding.' Ann Trop Med Parasitol. 2011;105:163-76.

20. Depaquit J, Bounamous A, Akhoundi M, Augot D, Sauvage F, Dvorak V, et al. A taxonomic study of Phlebotomus (Larroussius) perfiliewi s.l. Infect Genet Evol. 2013;20:500-8.

21. Latrofa MS, Dantas-Torres F, Weigl S, Tarallo VD, Parisi A, Traversa D, et al. Multilocus molecular and phylogenetic analysis of phlebotomine sand flies (Diptera: Psychodidae) from southern Italy. Acta Trop. 2011;119:91-8.

22. Thompson JD, Higgins DG, Gibson TJ. CLUSTAL W: improving the sensitivity of progressive multiple sequence alignment through sequence weighting, position-specific gap penalties and weight matrix choice. Nucleic Acids Res. 1994;22:4673-80.

23. Kumar S, Stecher G, Tamura K. MEGA7: molecular evolutionary genetics analysis version 7.0 for bigger datasets. Mol Biol Evol. 2016;33:1870-4.

24. Tamura K, Nei M. Estimation of the number of nucleotide substitutions in the control region of mitochondrial DNA in humans and chimpanzees. Mol Biol Evol. 1993;10:512-26.

25. Lanfear R, Frandsen PB, Wright AM, Senfeld T, Calcott B. PartitionFinder 2: new methods for selecting partitioned models of evolution for molecular and morphological phylogenetic analyses. Mol Biol Evol. 2016;34:772-3.

26. Ronquist F, Teslenko M, van der Mark P, Ayres DL, Darling A, Höhna S, et al. MrBayes 3.2: efficient Bayesian phylogenetic inference and model choice across a large model space. Syst Biol. 2012;61:539-42.

27. Guindon S, Dufayard J-F, Lefort V, Anisimova M, Hordijk W, Gascuel O. New algorithms and methods to estimate maximum-likelihood phylogenies: assessing the performance of PhyML 3.0. Syst Biol. 2010;59:307-21.

28. Yang Z. Computational molecular evolution. Oxford: University Press; 2006.

29. Huelsenbeck JP, Ronquist F. MRBAYES: Bayesian inference of phylogenetic trees. Bioinformatics. 2001;17:754-5.

30. Felsenstein J. Confidence limits on phylogenies: an approach using the bootstrap. Evolution. 1985;39:783-91.

31. Dvorak V, Halada P, Hlavackova K, Dokianakis E, Antoniou M, Volf P. Identification of phlebotomine sand flies (Diptera: Psychodidae) by matrixassisted laser desorption/ionization time of flight mass spectrometry. Parasit Vectors. 2014;7:21

32. Halada P, Hlavackova K, Dvorak V, Volf P. Identification of immature stages of phlebotomine sand flies using MALDI-TOF MS and mapping of mass spectra during sand fly life cycle. Insect Biochem Mol Biol. 2018;93:47-56. 
33. ICZN. International Commission on Zoological Nomenclature: Amendment of articles 8, 9, 10, 21 and 78 of the International Code of Zoological Nomenclature to expand and refine methods of publication. Bull Zool Nomencl. 2012;69:161-9.

34. Parrot L. Notes sur les phlébotomes. XIX. Phlébotomes de Crète. Arch Inst Pasteur Alger. 1936;14:50-2.

35. Adler S, Theodor O, Witenberg G. Investigations on Mediterranean kala azar. XI. A study of leishmaniasis in Canea (Crete). Proc R Soc Lond. 1938:125:491-516.

36. Ristorcelli A. Sur les phlébotomes de lîle de Crète. Ann Parasitol Hum Comp. 1939;17:355-8.

37. Hertig M. Phlebotomus and residual DDT in Greece and Italy. Am J Trop Med Hyg. 1949;s1-29:773-809.

38. Hadjinicolaou J. Present status of Phlebotomus in certain areas of Greece. Bull World Health Organ. 1958;19:967-79.

39. Pesson B, Wallon M, Floer MT, Kristensen AR. Isoenzymatic studies of Mediterranean populations of sandflies of the subgenus Larroussius. Parassitologia. 1991;33:471-6.

40. Léger N, Pesson B, Madulo-Leblond G, Ferté H, Tselentis Y, Antoniou M, Les phlébotomes de Crète $M$. Résultats d'une enquête entomologique effectuée en Juillet 1988 et Août 1989. Biol Gallo-hell. 1993;20:135-43.

41. Chaniotis B, Spyridaki I, Scoulika E, Antoniou M. Colonization of Phlebotomus neglectus (Diptera: Psychodidae), the major vector of visceral leishmaniasis in Greece. J Med Entomol. 2000;37:346-8.

42. Ivović $V$, Patakakis M, Tselentis $Y$, Chaniotis B. Faunistic study of sandflies in Greece. Med Vet Entomol. 2007;21:121-4.

43. Ivović V, Chaniotis V, Vujanić M, Bobić B, Nikolić A, Klun I, et al. Life tables and reproductive parameters of Phlebotomus neglectus Tonnoir, 1921 (Diptera, Psychodidae) under laboratory conditions. Arch Biol Sci. 2010;62:153-7.

44. Christodoulou V, Antoniou M, Ntais P, Messaritakis I, Ivović V, Dedet J-P, et al. Re-emergence of visceral and cutaneous leishmaniasis in the Greek Island of Crete. Vector Borne Zoonotic Dis. 2012;12:214-22.

45. Alten B, Maia C, Afonso MO, Campino L, Jiménez M, González E, et al. Seasonal dynamics of phlebotomine sand fly species proven vectors of Mediterranean leishmaniasis caused by Leishmania infantum. PLoS Negl Trop Dis. 2016;10:e0004458

46. Langeron M. Phlébotomes capturés en Crète. Ann Parasitol Hum Comp. 1923;1:108.

47. Aransay AM, Scoulica E, Chaniotis B, Tselentis Y. Typing of sandflies from Greece and Cyprus by DNA polymorphism of 185 rRNA gene. Insect Mol Biol. 1999:8:179-84.

48. Blanc G, Caminopetros J. Enquiry into Oriental sore in Crete. Reflections suggested on the etiology and mode of dispersion of the disease. Ann Inst Pasteur. 1921;35:151-66.

49. Kasap OE, Dvorak V, Depaquit J, Alten B, Votypka J, Volf P. Phylogeography of the subgenus Transphlebotomus Artemiev with description of two new species, Phlebotomus anatolicus n. sp. and Phlebotomus killicki n. sp. Infect Genet Evol. 2015:34:467-79.

50. Birt C. Phlebotomus fever in Malta and Crete. J R Army Med Corps. $1910: 14 \cdot 236-58$
51. Depaquit J, Ferté H, Léger N, Lefranc F, Alves-Pires C, Hanafi H, et al. ITS 2 sequences heterogeneity in Phlebotomus sergenti and Phlebotomus similis (Diptera, Psychodidae): possible consequences in their ability to transmit Leishmania tropica. Int J Parasitol. 2002;32:1123-31.

52. Depaquit J, Léger N, Ferté H. Le statut taxinomique de Phlebotomus sergenti Parrot, 1917, vecteur de Leishmania tropica (Wright, 1903) et Phlebotomus similis Perfiliev, 1963 (Diptera-Psychodidae). Approches morphologique et morphométrique. Corollaires biogéographiques et épidémiologiques. Bull Soc Pathol Exot. 1998:91:346-52.

53. Killick-Kendrick R. Phlebotomine vectors of the leishmaniases: a review. Med Vet Entomol. 1990;4:1-24.

54. Depaquit J, Grandadam M, Fouque F, Andry PE, Peyrefitte C. Arthropodborne viruses transmitted by phlebotomine sandflies in Europe: a review. Euro Surveill. 2010:15:19507.

55. Alwassouf S, Christodoulou V, Bichaud L, Ntais P, Mazeris A, Antoniou $M$, et al. Seroprevalence of sandfly-borne phleboviruses belonging to three serocomplexes (Sandfly fever Naples, Sandfly fever Sicilian and Salehabad) in dogs from Greece and Cyprus using neutralization test. PLoS Negl Trop Dis. 2016;10:e0005063.

56. Sadlova J, Dvorak V, Seblova V, Warburg A, Votypka J, Volf P. Sergentomyia schwetzi is not a competent vector for Leishmania donovani and other Leishmania species pathogenic to humans. Parasit Vectors. 2013;6:186.

57. Maia C, Depaquit J. Can Sergentomyia (Diptera, Psychodidae) play a role in the transmission of mammal-infecting Leishmania? Parasite. 2016;23:55.

58. Maia C, Parreira R, Cristóvão JM, Freitas FB, Afonso MO, Campino L. Molecular detection of Leishmania DNA and identification of blood meals in wild caught phlebotomine sand flies (Diptera: Psychodidae) from southern Portugal. Parasit Vectors. 2015;8:173.

59. Artemiev MM, Neronov VM. Distribution and ecology of sandflies of the old world: genus Phlebotomus. Moscow: USSR Academy of Sciences; 1984

60. Esseghir S, Ready PD, Ben-Ismail R. Speciation of Phlebotomus sandflies of the subgenus Larroussius coincided with the late Miocene-Pliocene aridification of the Mediterranean subregion. Biol J Linn Soc. 2000;70:189-219.

61. Yssouf A, Almeras L, Raoult D, Parola P. Emerging tools for identification of arthropod vectors. Future Microbiol. 2016;11:549-66.

62. Depaquit J, Ferte H, Leger N, Killick-Kendrick R, Rioux JA, Killick-Kendrick $M$, et al. Molecular systematics of the phlebotomine sandflies of the subgenus Paraphlebotomus (Diptera, Psychodidae, Phlebotomus) based on ITS2 rDNA sequences. Hypotheses of dispersion and speciation. Insect Mol Biol. 2000;9:293-300.

\section{Publisher's Note}

Springer Nature remains neutral with regard to jurisdictional claims in published maps and institutional affiliations.
Ready to submit your research? Choose BMC and benefit from:

- fast, convenient online submission

- thorough peer review by experienced researchers in your field

- rapid publication on acceptance

- support for research data, including large and complex data types

- gold Open Access which fosters wider collaboration and increased citations

- maximum visibility for your research: over 100M website views per year

At BMC, research is always in progress.

Learn more biomedcentral.com/submissions 